\title{
P-106
}

\section{Antiulcer and Antibacterial Evaluations of Illicium Verum Ethanolic Fruits Extract (IVEFE)}

\author{
Jamal Hussaini ${ }^{1, *}$, Nurul Asyikin Othman ${ }^{2}$ and Mahmood Ameen Abdulla \\ ${ }^{1}$ Faculty of Medicine, Universiti Teknologi MARA (UiTM), 40450 Shah Alam, Selangor, Malaysia; ${ }^{2}$ Department of \\ Molecular Medicine, Faculty of Medicine, University of Malaya, 50603, Malaysia; E-mail: jamalh@salam.uitm.edu.my
}

Illicium verum, or commonly known as "bunga lawang" is widely used in Malaysia for cooking. Current study was carried out to evaluate the potential antiulcer and antibacterial activity within Illicium verum ethanolic fruit extract (IVEFE). Four groups of rats were pre-treated with carboxymethyl cellulose (negative control group), omeprazole $20 \mathrm{mg} / \mathrm{kg}$ (positive control group), 250 and $500 \mathrm{mg} / \mathrm{kg}$ of IVEFE an hour before absolute ethanol were administered to induce gastric ulcer. An hour later, the rats were sacrificed, and the evaluation of ulcer areas, $\mathrm{pH}$ of gastric content, mucus production and histology of gastric mucosa were done. Antibacterial activity of the extract was done by disc diffusion method using three gram positive and three gram negative bacteria. Minimum inhibitory concentration (MIC) and minimum bactericidal concentration (MBC) were also tested.

Negative control group exhibited severe mucosal injury, while the groups pre-treated with the IVEFE shows milder injury. This is consistent with the increment of mucus production and $\mathrm{pH}$ of gastric content, as well as histology findings. Antibacterial activity studies showed zone of inhibition ranging between (7.0-11.0mm), MIC (4.69-9.38 mg/ml) and MBC (4.69-9.38 mg/ml) were evaluated. As conclusion, Illicium verum possess antiulcer and antibacterial activities. However, further studies need to be taken to evaluate the potential of this plant as a replacement of therapy.

Keywords: Illicium verum, antiulcer, antibacterial, MIC, MBC. 